\title{
Desenvolvimento das Raízes do Azevém Cultivado em Solução Nutritiva Completa, Adicionada de Substâncias Húmicas, sob Condições de Casa de Vegetação1
}

\author{
Ricardo Muñoz da Silva², André Jablonski ${ }^{3}$, Lotar Siewerdt ${ }^{4}$, Paulo Silveira Júnior ${ }^{5}$
}

\begin{abstract}
RESUMO-Este estudo foi realizado em casa de vegetação, no ano de 1997, na Faculdade de Agronomia da Universidade Federal do Rio Grande do Sul (UFRGS). Emum desenho experimental de blocos casualizados com parcelas divididas e seis repetições, foram avaliadas as seguintes variáveis: comprimento das raízes, raio médio, superfície ocupada e matéria seca produzida pelas raízes do azevém, visando avaliar o efeito da adição de substâncias húmicas no desenvolvimento das raízes do azevém. As plantas foram cultivadas em areia irrigada, com uma solução nutritiva completa e quatro doses de substâncias húmicas (0, 10, 20 e 30-mg/litro), extraídas a partir dos carvões das minas do Capané (Palermo CE-4.200 e Palermo CE-4.700), Leão (Leão CE-5.200) e Candiota (Candiota Camada Superior, Candiota Camada Inferior, Candiota CE-3.300 e Candiota CE-4.700). Para todas as variáveis analisadas a análise estatística acusou significância para os efeitos da interação doses x matéria-prima. Os resultados demonstraram que as substâncias húmicas promoveram o desenvolvimento das raízes aumentando: a) em 100,87\% o comprimento da raiz; b) em $49,23 \%$ o peso das raízes e c) em $68 \%$ a superfície ocupada pelas raízes. Conclui-se que as substâncias húmicas promoveram o desenvolvimento das raízes do azevém e as distintas fontes destas substâncias agiram de forma diferente sobre os parâmetros das quatro variáveis analisadas.
\end{abstract}

Palavras-chave: ácidos fúlvicos, ácidos húmicos, carvão, Lolium multiflorum

\section{Development of Ryegrass Roots as Affected by Humic Compounds Addition to a Complete Nutritive Solution Under Greenhouse Conditions}

\begin{abstract}
This work was carried out under greenhouse conditions, in 1997, at Faculdade de Agronomia, Universidade Federal do Rio Grande do Sul (UFRGS). A split plot randomized complete block experimental design was used, with six replications, to evaluate root lengths, average radius, roots surface and dry matter of roots with the objective to evaluate the effect of humic compounds addition in the development of ryegrass roots. Ryegrass forage was grown in pots with irrigated sand with four levels of humic compounds added to a complete nutritive solution with four-doses of humic compounds $(0,10,20$ and $30-\mathrm{mg} / \mathrm{liter})$. The humic compounds were extracted from the charcoals of the Capané (Palermo CE-4,200 and Palermo CE-4,700), Leão (Leão CE-5,200) and Candiota (Candiota superior layer, Candiota inferior layer, CE-3,300 and Candiota CE-4,700) mines. For all variables, the statistical analyses showed significance for the interaction dose $\mathrm{x}$ raw material effects. Results demonstrated that humic compounds promoted roots development, increasing: a) roots length at $100,87 \%$; b) roots weight at $49,23 \%$ and c) $68 \%$ of the roots surface. The humic compounds influence ryegrass roots development and that these substances from different raw materials distinctly act on the parameters of the four variables analyzed.
\end{abstract}

Key Words: fulvic acid, humic acid, coal, Lolium multiflorum

\section{Introdução}

Efeitos benéficos das substâncias húmicas sobre o crescimento de plantas e do sistema radicular têm sido reconhecidos em muitos trabalhos, mas efeitos específicos destas substâncias sobre as várias partes das plantas e estádios de crescimento ainda não foram adequadamente investigados. Ácidos húmicos e fúlvicos em soluções nutritivas são utilizados na Europa, tanto em hidroponia como em gotejamento, sendo usadas quantidades de 10-20 kg/ha/ano de matéria húmica (BRUN, 1993). Estas práticas permitem menor uso de insumos e produção mais equilibrada ecologicamente. Quimicamente o material original do carvão é semelhante ao que constitui a matéria orgânica do solo, como celulose, hemicelulose, lignina e, em menor quantidade, proteínas, açucares, pentosanas, pectinas, taninos e substâncias betuminosas. Os grupos funcionais predominantes nas substâncias húmicas são os oxigenados, princi-

\footnotetext{
1 Trabalho parcialmente financiado pela FAPERGS e pela Fundação Banco do Brasil e pelo CNPq, com apoio da Empresa JOSAPAR - Joaquim Oliveira S.A. Participações.

2 Engo.-Agro. MSc. Doutorando do PPGEM - EE - UFRGS - fone (0XX51)360-8207. E.mail: rmunoz@dali.ppgem.ufgrs.br. Endereço para correspondência: CP. 354, CEP 96001-970 - Pelotas, RS - A/C Prof. Lotar Siewerdt. E.mail: lotar@ufpel.tche.br

3 Geólogo, PhD. Prof. Adjunto, DEMIN - Escola de Engenharia.

4 Engo.-Agro. PhD. Professor Titular, Departamento de Zootecnia - FAEM - UFPEL.

5 Engo-Agro. Dr. Prof. Titular. Instituto de Física e Matemática. UFPEL.
} 
palmente carboxílicos $(\mathrm{COOH})$, hidroxílas $(\mathrm{OH})$, carbonilas $(\mathrm{C}=\mathrm{O})$, metóxilas $(\mathrm{OCH} 3)$ e ocasionalmente esteres (COOR) e éteres (COC) (HAYES et al., 1989). A resposta das plantas aos ácidos húmicos e fúlvicos está na dependência da matéria-prima original e, principalmente, da espécie vegetal. Matérias-primas orgânicas diversas apresentam em sua composição ácidos húmicos e ácidos fúlvicos diferentes, bem como distintas concentrações desses ácidos húmicos e fúlvicos (BRUN, 1993). Estes ácidos orgânicos podem ser facilmente extraídos do carvão mineral, são baratos, não-poluentes e apresentam eficiência no desenvolvimento de diversas culturas (XUDAN, 1986).

O desenvolvimento da parte aérea das raízes e a absorção de nutrientes da cevada é estimulado por substâncias húmicas originadas de diferentes fontes orgânicas (lodo de esgoto, composto orgânico, leonardita, turfa e ácidos húmicos comerciais) em níveis de até $10 \mathrm{mg}$ de carbono por litro, sendo que em dosagens elevadas o desenvolvimento é deprimido (AYUSO et al., 1996). Já GOENADI e SUDHARAMA (1995), em cultura de tecidos, visando produção de mudas de espécies tropicais, testaram diversas dosagens de ácidos húmicos extraídos de solos orgânicos tendo cada espécie respondido a uma dosagem ideal. Assim, 400, 40 e 300 mg/L promoveram o melhor crescimento radicular de Gnetum gnemon, Elletaria cardamomum e Pogostemon cablin, respectivamente.

O mecanismo de estimulação de ácidos húmicos e fúlvicos sobre o elongamento do sistema radicular não foi investigado neste estudo. Entretanto, outros trabalhos têm sugerido a possibilidade da existência de diversos mecanismos. MAGGIONI et al. (1987) indicou que os ácidos húmicos e fúlvicos podem influenciar a absorção de nutrientes via um efeito enzimático, por intermédio da atividade de ATPase dependente de $\mathrm{K}^{+}$ e $\mathrm{Mg}^{2+}$. SAMSON e VISSER (1989) demonstraram que a permeabilidade da membrana plasmática pode ser alterada por estes ácidos. PINTON et al. (1992) demonstraram que estas substâncias húmicas afetam a atividade da ATPase microssomal e do tonoplasto, confirmando as observações feitas por MAGGIONI et al. (1987). Em quantidades de até $0,5 \mathrm{mg}$ de $\mathrm{C}$ por $\mathrm{cm}^{3}$, as substâncias húmicas estimularam estas enzimas em aveia, sendo que, em dosagens superiores, o efeito foi deletério. Existe uma associação entre enzimas e substâncias húmicas e o resultado desta associação leva ao estímulo da atividade de muitas enzimas (fosforilase, fosfatase, citocromo oxidase), à inibição de outras (IAA oxidase, fitase e peroxidase) e à síntese de enzimas (invertase) (PEREIRA e MÉNDEZ, 1976; POSPÍSIL e HRUBCOVA, 1974; e VAUGHAN e ORD, 1980). Desde 1917 já se sabe que estas substâncias apresentam uma ação sobre as plantas semelhante às auxinas e, em 1982, foram isolados ácidos húmicos que apresentaram efeito semelhante às giberelinas em Raphanus sativus (PETROVIC et al., 1982).

O azevém está entre no grupo 1 da classificação de KHRISTEWA (1953), caracterizado por plantas folhosas e ricas em glicídios, podendo apresentar resposta superior ou igual a 50\%. Produtos comerciais de substâncias húmicas têm obtido resultados em várias culturas, como abóbora. SMIDOVA (1960) obteve aumento maior que $61 \%$ sobre a produção e RHAUTHAN e SCHINITZER (1981), aumento de até $37 \%$ sobre o comprimento radicular, $125 \%$ sobre o peso das raízes e $142 \%$ sobre a produção da parte aérea), cevada (12-17\%, RAM e VERLOO, 1983). Os resultados obtidos são variáveis e dependem das substâncias húmicas utilizadas, da concentração, do grau de purificação do material e das condições em que foram realizados os experimentos, além da espécie testada. O uso de substâncias húmicas extraídas de carvão beneficiado pela mina do Capané (Palermo CE-4.200), em um experimento na Faculdade de Agronomia da Universidade Federal do Rio Grande do Sul, utilizando as dosagens $0,10,20$ e $30 \mathrm{mg}$ de carbono por litro adicionadas a uma solução nutritiva completa, permitiu produção $226,73 \%$ superior de matéria seca da parte aérea da cultivar de alface "Baba de verão", produzindo sistemas radiculares com peso de raízes $240 \%$ superiores. Verificou-se que a dosagem de $30 \mathrm{mg}$ de substâncias húmicas do carvão Capané Palermo CE-4.200 permite produção maior e promove em alface maior desenvolvimento do sistema radicular que as dosagens 0,10 e $20 \mathrm{mg} / \mathrm{L}$ (SILVA e JABLONSKI, 1995). A presença destes ácidos permitem melhor desenvolvimento do sistema radicular, quando se compara com o cultivo na sua ausência. Os ácidos fúlvicos apresentam resposta em concentrações mais elevadas que os ácidos húmicos.

Os objetivos do presente trabalho foram avaliar o desenvolvimento das raízes da forrageira azevém (Lolium multiflorum L.) com solução nutritiva e quatro dosagens de substâncias húmicas extraídas de carvões do Rio Grande do Sul; gerar subsídios para estudos de viabilidade de implantação de uma unidade industrial para a produção de substâncias húmicas no Estado do Rio Grande do Sul; e gerar subsídios para cultivos que utilizem como técnica de produção a hidroponia, o gotejamento ou a fertirrigação. 


\section{Material e Métodos}

Foram coletadas amostras representativas de carvão em três minas em funcionamento no Estado do Rio Grande do Sul, Candiota (Camada Superior, Camada Inferior, CE-3.300 e CE-4.700), Capané (Palermo CE-4.200, CE-4.700) e Leão (CE-5.200). Os carvões Candiota Camada Superior e Camada Inferior foram coletados nas respectivas camadas de carvão da mina de Candiota e os beneficiados, nas pilhas dos respectivos carvões lavados localizados nos pátios de armazenagem das minas. As amostras de carvão foram secas ao ar livre e acondicionadas em sacos plásticos. As amostras foram moídas em moinho de disco com disco e cápsulas de alumina, até uma granulometria inferior a $0,025 \mathrm{~mm}$ e armazenadas em frasco plásticos e mantidas em dessecador até o tratamento de reidratação e lavagem com solução de $\mathrm{HCl}$ 0,5 M, para extração de carbonatos e íons metálicos. As amostras de carvão foram caracterizadas (análise imediata) determinando-se teores de cinza (ABNT NBR 8289), umidade (ABNT NBR 8293), enxofre nas formas pirítico, sulfático e orgânico (ABNT NBR 8297), enxofre total (ISO 334-1975), matéria volátil (ABNT NBR 8290) e carbono fixo (ABNT NBR 8289), no Laboratório de Geoquímica Ambiental da Escola de Engenharia da Universidade Federal do Rio Grande do Sul (LAGEAMB-EEPPGEM-UFRGS). Os resultados destas análises encontram-se na Tabela 1, tendo sido semelhantes aos obtidos por SILVA et al. (1995a).

As substâncias húmicas foram extraídas dos carvões moídos com KOH 1M, após tratamentos prévios com $\mathrm{HCl} \mathrm{e} \mathrm{H}_{3} \mathrm{PO}_{4}$ 0,5 $\mathrm{M}$, como apresentado na
Figura 1. Após esta extração foi feita a caracterização do extrato quanto a $\mathrm{pH}$, densidade, concentração em $\mathrm{g} / \mathrm{L}$, acidez titulável da matéria seca do extrato, teores de carbono e nitrogênio e teor de cinzas (TEDESCO et al., 1995), cujos resultados estão contidos na Tabela 2.

Este experimento com azevém foi conduzido em casa de vegetação utilizando o desenho experimental de blocos casualisados, em parcelas subdivididas, com seis repetições. Nas parcelas foram alocados os cortes; nas subparcelas; as sete matérias-primas; e as dosagens, nas sub-subparcelas. As plantas foram cultivadas com solução nutritiva completa e quatro doses de substâncias húmicas $(0,10,20$ e 30-mg/L), extraídas a partir de carvões. Os quatro tratamentos que constituíram as dosagens foram os seguintes: $\mathrm{T}_{1}=$ Solução nutritiva $(\mathrm{SN})+0-\mathrm{mg} / \mathrm{L}$ de substâncias húmicas $(\mathrm{SH}) ; \mathrm{T}_{2}=\mathrm{SN}+10-\mathrm{mg} / \mathrm{L}$ de $\mathrm{SH}$; $\mathrm{T}_{3}=\mathrm{SN}+20-\mathrm{mg} / \mathrm{L}$ de $\mathrm{SH}$ e $\mathrm{T}_{4}=\mathrm{SN}+30-\mathrm{mg} / \mathrm{L}$ de SH. As mg/L de substâncias húmicas, são equivalentes em $\mathrm{mg} / \mathrm{L}$ de carbono do extrato obtido a partir da determinação do teor de carbono pelo método de Walkley Black segundo TEDESCO et al. (1995).

O experimento foi implantado em 26.05.97, sendo feitos quatro cortes $(27.07 .97,29.08 .97,29.09 .97 \mathrm{e}$ 30.10.97). Foi utilizada a cultivar comum do azevém, semeada na base de 1 grama de semente por vaso plástico, com cinco litros de capacidade, enchido com areia lavada até $1 \mathrm{~cm}$ da borda.

A solução nutritiva utilizada apresentava as seguintes concentrações: $78 \mathrm{mg} / \mathrm{L}$ de $\mathrm{K}, 70 \mathrm{mg} / \mathrm{L} \mathrm{de} \mathrm{Cl}$, $24 \mathrm{mg} / \mathrm{L}$ de $\mathrm{Mg}, 32 \mathrm{mg} / \mathrm{L}$ de S-SO4, $15 \mathrm{mg} / \mathrm{L}$ de $\mathrm{P}$, $63 \mathrm{mg} / \mathrm{L}$ de N, $60 \mathrm{mg} / \mathrm{L}$ de Ca, $5 \mathrm{mg} / \mathrm{L}$ de Fe-EDTA, $0,25 \mathrm{mg} / \mathrm{L}$ de $\mathrm{Mn}, 0,3 \mathrm{mg} / \mathrm{L}$ de $\mathrm{Cu}, 0,1 \mathrm{mg} / \mathrm{L}$ de $\mathrm{Zn}$,

Tabela 1 - Resultados da análise imediata das matérias-primas testadas (\% base seca) Table 1 - Chemical composition of raw-materials evaluated (dry matter basis \%)

\begin{tabular}{|c|c|c|c|c|c|c|c|c|c|}
\hline $\begin{array}{l}\text { Amostras } \\
\text { Samples }\end{array}$ & $S_{t}$ & $S_{\text {pir }}$ & $S_{\mathrm{SO} 4}$ & $S_{o}$ & $C_{f i x}$ & $W_{t}$ & $W_{h}$ & $A$ & $M V$ \\
\hline Candiota C. Inf. & 1,18 & 0,98 & 0,07 & 0,13 & 23,05 & 16,13 & 1,92 & 48,03 & 27,00 \\
\hline Candiota C. Sup. & 1,26 & 0,98 & 0,11 & 0,17 & 20,30 & 16,15 & 2,41 & 51,18 & 26,11 \\
\hline Candiota CE-4700 & 0,93 & 0,79 & 0,06 & 0,08 & 34,07 & 16,46 & 1,90 & 35,03 & 29,00 \\
\hline Candiota CE-3300 & 1,01 & 0.83 & 0.08 & 0,10 & 26,74 & 16,17 & 1,49 & 43,43 & 28,34 \\
\hline Leão CE-5200 & 0,26 & 0,17 & 0,04 & 0,05 & 34,01 & 17,01 & 1,80 & 30,09 & 34,10 \\
\hline Palermo CE-4700 & 1,00 & 0,35 & 0,55 & 0,10 & 28,09 & 16,36 & 1,58 & 41,00 & 29,33 \\
\hline Palermo CE-4200 & 0,59 & 0,39 & 0,08 & 0,12 & 26,05 & 16,80 & 1,55 & 43,04 & 29,36 \\
\hline \multicolumn{2}{|l|}{$\begin{array}{l}\text { St - enxofre total } \\
S_{O} \text { - enxofre orgânico } \\
\text { A - cinza } \\
S t \text { - total sulfur } \\
S_{O} \text { - organic sulfur } \\
A \text { - ash }\end{array}$} & \multicolumn{3}{|c|}{$\begin{array}{l}S_{\text {pir }} \text { - enxofre pirítico } \\
W_{t} \text { - umidade total } \\
M V \text { - matéria volátil } \\
S_{\text {pir }} \text { - piritic sulfur } \\
W_{t} \text { - total moisture } \\
M V \text { - volatile matter }\end{array}$} & & $\begin{array}{l}\mathrm{S}_{\mathrm{SO} 4} \\
\mathrm{~W}_{\mathrm{h}} \\
\mathrm{C}_{\mathrm{fix}} \\
S_{\mathrm{SO}} \\
W_{h} \\
C_{f i x}\end{array}$ & \multicolumn{3}{|c|}{$\begin{array}{l}\text { - enxofre sulfático } \\
\text { - umidade higroscó } \\
\text { - carbono fixo } \\
\text { - sulfatic sulfur } \\
\text { - higroscopic moisture } \\
\text { - fixed carbon }\end{array}$} \\
\hline
\end{tabular}


SILVA et al.

Tabela 2 - Resultados das características físico-químicas dos extratos de substâncias húmicas obtidas (teores em \% da matéria seca)

Table 2 - Chemical and physical characteristics of humic compounds (contents based in dry matter basis-\%)

\begin{tabular}{|c|c|c|c|c|}
\hline $\begin{array}{l}\text { Amostras } \\
\text { Samples }\end{array}$ & $\begin{array}{l}\mathrm{pH} \\
\mathrm{pH}\end{array}$ & $\begin{array}{l}\text { Conc. g/L } \\
\text { Conc. } g / L\end{array}$ & $\begin{array}{c}\text { Densidade } \\
\text { Density }\end{array}$ & $\begin{array}{c}\text { Produção } \% \\
\text { Yield }^{*}\end{array}$ \\
\hline Candiota Camada Inferior & 13,54 & 22,85 & 1,018 & 17,66 \\
\hline Candiota Camada Superior & 12,18 & 22,63 & 1,018 & 17,39 \\
\hline Candiota CE-4700 & 12,06 & 26,65 & 1,018 & 21,08 \\
\hline Candiota CE-3300 & 12,11 & 25,42 & 1,019 & 19,54 \\
\hline Leão CE-5200 & 12,54 & 26,18 & 1,019 & 10,26 \\
\hline Palermo CE-4700 & 13,60 & 53,78 & 1,057 & 22,68 \\
\hline Palermo CE-4200 & 13,70 & 43,98 & 1,045 & 23,58 \\
\hline $\begin{array}{l}\text { Amostras } \\
\text { Samples }\end{array}$ & $\% \mathrm{C}$ & $\% \mathrm{~N}$ & $\mathrm{C}: \mathrm{N}$ & $\begin{array}{c}\text { Cinzas-\% } \\
\text { Ashes-\% }\end{array}$ \\
\hline Candiota Camada Inferior & 42,39 & 0,83 & 51,07 & 47,77 \\
\hline Candiota Camada Superior & 40,01 & 0,79 & 50,65 & 45,94 \\
\hline Candiota CE-4700 & 44,56 & 1,01 & 44,11 & 44,35 \\
\hline Candiota CE-3300 & 43,34 & 0,93 & 46,60 & 46,37 \\
\hline Leão CE-5200 & 44,87 & 0,39 & 115,05 & 48,79 \\
\hline Palermo CE-4700 & 44,34 & 0,54 & 82,11 & 40,78 \\
\hline Palermo CE-4200 & 43,83 & 0,53 & 82,69 & 38,74 \\
\hline Amostras & Acidez & \%ácidos & \%ácidos & Total \\
\hline \multirow[t]{2}{*}{ Samples } & titulável & húmicos & fúlvicos & Total \\
\hline & $\begin{array}{l}\text { Titrable } \\
\text { acidity }\end{array}$ & $\begin{array}{c}\% \text {-humic } \\
\text { acids }\end{array}$ & $\begin{array}{c}\% \text {-fulvic } \\
\text { acids }\end{array}$ & \\
\hline Candiota Camada Inferior & 465,59 & 3,48 & 1,94 & 5,42 \\
\hline Candiota Camada Superior & 504,62 & 3,92 & 2,06 & 5,98 \\
\hline Candiota CE-4700 & 621,94 & 4,44 & 2,52 & 6,96 \\
\hline Candiota CE-3300 & 552,45 & 3,97 & 2,22 & 6,19 \\
\hline Leão CE-5200 & 658,23 & 3,88 & 1,38 & 5,24 \\
\hline Palermo CE-4700 & 527,79 & 5,52 & 2,26 & 7,78 \\
\hline Palermo CE-4200 & 481,01 & 3,14 & 1,96 & 5,10 \\
\hline
\end{tabular}

$1,25 \mathrm{mg} / \mathrm{L}$ de $\mathrm{B}$ e $0,01 \mathrm{mg} / \mathrm{L}$ de $\mathrm{Mo}$.

O corte foi realizado em 30.10 .97 , separando-se em parte aérea e raízes. O material foi pesado e $75 \%$ do sistema radicular foi seco em estufa com ar forçado a $65^{\circ} \mathrm{C}$ e, após, moído e a matéria seca total, determinada em estufa a $105^{\circ} \mathrm{C}$ por uma hora. A parcela das raízes utilizada para determinação do respectivo comprimento (25\%) foi armazenada em sacos plásticos por três dias em geladeira para a determinação pelo método de TENNANT (1975), utilizando quadrículas de $1 \mathrm{~cm}$ e a formula $=11 / 14 \mathrm{x}$ $1 \mathrm{~g} \mathrm{x} \mathrm{n}^{\circ}$ de internódios $\mathrm{x}$ matéria verde das raízes. $\mathrm{O}$ raio médio das raízes foi obtido pela fórmula: $\mathrm{R}_{0}^{2}=$ volume de raízes $=($ matéria verde $) / \mathrm{p} \times \mathrm{L}$ (comprimento das raízes). A superfície ocupada pelas raízes ( $\mathrm{S}$ ) foi calculada por meio da fórmula: $S=2 p \times R \times$. $L$.

Os resultados foram analisados estatisticamente utilizando-se o programa SANEST (ZONTA e MACHADO, 1984), aplicando-se a análise de regressão polinomial para a interação entre matérias-primas e as diversas doses utilizadas.

\section{Resultados e Discussão}

Os teores purificados de ácidos húmicos e fúlvicos obtidos foram baixos e os extratos apresentaram alta acidez titulável em cmol/c/kg (Tabela 2), mas estão de acordo com aqueles obtidos por SILVA et al. (1995b).

\section{Produção de matéria seca das raízes}

Para esta variável a análise de variância apresentou significância para os efeitos da interação doses $\mathrm{x}$ matérias-primas utilizadas como fontes de substâncias húmicas $(\mathrm{P}<0,01)$, com $\mathrm{CV}(\mathrm{a})=1,40 \% \mathrm{e}$ $\mathrm{CV}(\mathrm{b})=3,24 \%$. As equações de regressão polinomiais da interação encontram-se na Tabela 3 , tendo sido obtida resposta quadrática para as dosagens em todas as matérias-primas testadas. As curvas de regressão apresentaram os seguintes pontos de máxima: Palermo CE-4700 (9,94 g na dose de 15,11 mg de carbono por litro); Candiota CE-4700 (9,82 g na dose de 15,02 mg/L); Leão CE-5200 (8,95 g e na dosagem de 15,26 mg/L), Candiota Camada Inferior $(9,99 \mathrm{~g}$ na dose de $15,11 \mathrm{mg} / \mathrm{L})$; Candiota Camada 
Rev. bras. zootec.

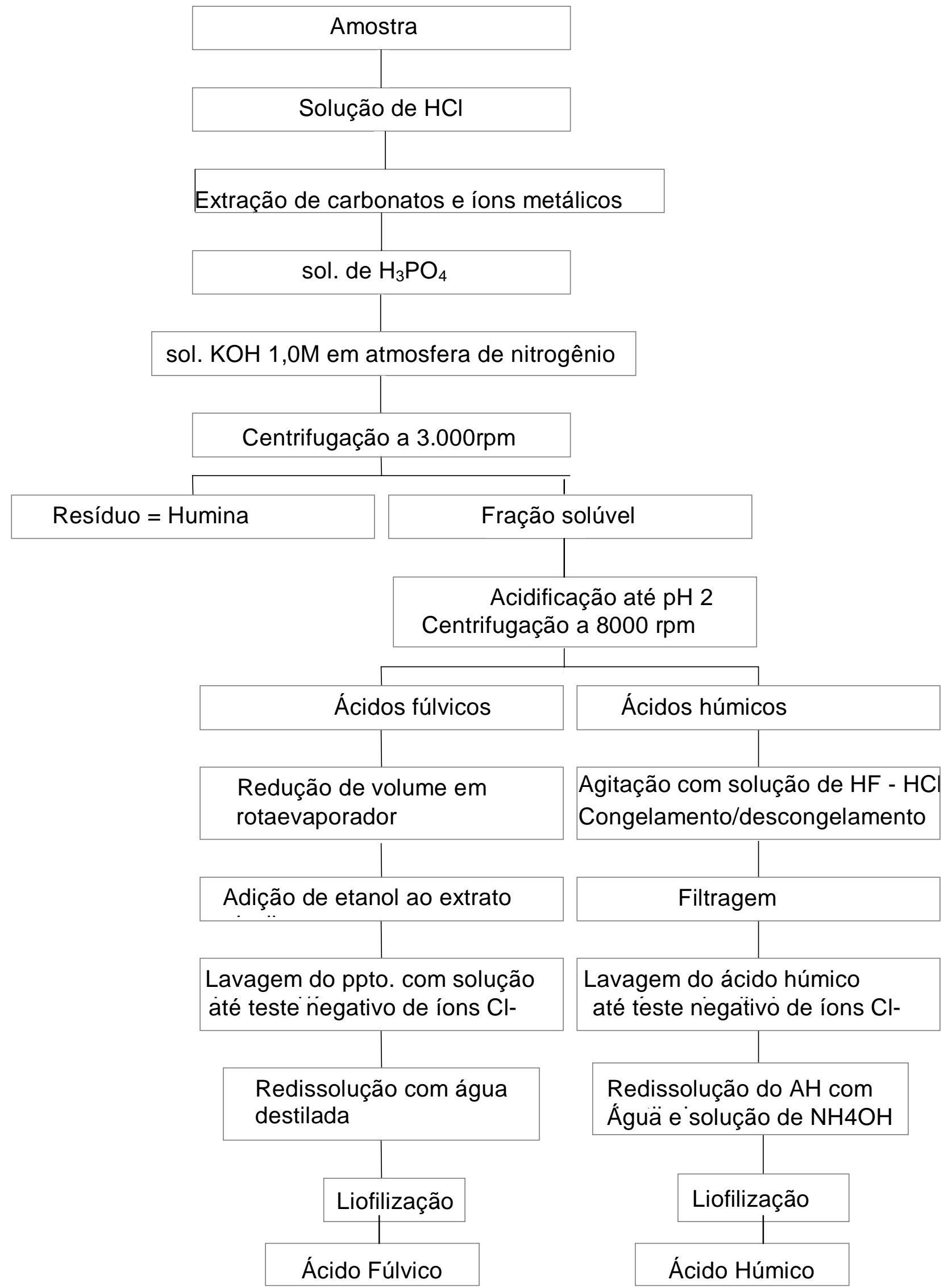

Figura 1 - Esquema da extração, fracionamento e purificação dos ácidos húmicos e fúlvicos.

Figure 1 - Scheme of extraction, fractioning and purification of fulvic and humic acids. 
Superior (10,18 g na dose 15,45 mg/L); Palermo CE4200 (9,85 g na dosagem de $15,38 \mathrm{mg} / \mathrm{L})$ e Candiota CE-3300 ( 14,88 g na dose de 9,57 mg/L). Os resultados sugerem, neste caso, o uso de dosagens entre 10 e $20 \mathrm{mg} / \mathrm{L}$ (Tabela 3). Estas dosagens foram eficientes para aumentar a produção de matéria seca das raízes em 49,23\%. Como no trabalho de PINTON et al. (1992), também neste experimento os ácidos responderam positivamente até certa dosagem. Os coeficientes de determinação $\left(\mathrm{R}^{2}\right)$ obtidos indicaram que mais de $85 \%$ da variação observada foi atribuída ao efeito dos tratamentos (doses de substâncias húmicas). Os resultados comprovam existir maior desenvolvimento das raízes em presença de substâncias húmicas (RHAUTHAN e SCHNITZER, 1981; SILVA e JABLONSKI, 1995; e SILVA et al., 1998a), corroborando informações da literatura mundial.

\section{Comprimento das raízes}

O comprimento das raízes acusou significância para o efeito da interação matérias-primas $\mathrm{x}$ doses $(\mathrm{P}<0,01)$, com $\mathrm{CV}$ (a) $2,71 \%$ e $\mathrm{CV}(\mathrm{b})=6,15 \%$. O resultado da análise de regressão polinomial para a interação matérias-primas testadas $\mathrm{x}$ doses é apresentado na Tabela 3. As curvas de regressão apresentaram os seguintes pontos de máximo comprimento:
Palermo CE-4700 (59.301,93 cm na dose de 22,49 mg de carbono por litro); Candiota CE-4700 (62.428,35 cm na dose de 35,47 mg/L); Leão CE-5200 (58.651,39 cm na dosagem de 23,44 mg/L), Candiota Camada Inferior $(56.996,15 \mathrm{~cm}$ na dose de $25,83 \mathrm{mg} / \mathrm{L})$; Candiota Camada Superior (58.192,41 cm na dose 26,41 mg/L); Palermo CE-4200 $(58.940,34 \mathrm{~cm}$ na dosagem de $22,38 \mathrm{mg} / \mathrm{L})$ e Candiota CE-3300 (58.191,30 cm na dose de 27,56 mg/L). Os resultados demonstram que as substâncias húmicas favoreceram o crescimento das raízes, aumentando em 100,87\%, quando a dose de substâncias húmicas passou de 0 para $20 \mathrm{mg} / \mathrm{L}$. Estas substâncias apresentam efeitos positivos sobre o metabolismo das plantas, estimulando o alongamento das raízes (os coeficientes de determinação das equações obtidas indicam que mais de $90 \%$ do elongamento radicular foi devido ao efeito das substâncias húmicas).

\section{Raio médio das raízes}

A análise de variância para esta variável apresentou significância para o efeito da interação matéria-primas $\mathrm{x}$ doses $(\mathrm{P}<0,01), \operatorname{com} \mathrm{CV}(\mathrm{a})=0,92 \%$ e $\mathrm{CV}(\mathrm{b})=2,57 \%$. Os resultados da interação matériasprimas $\mathrm{x}$ doses encontram-se na Tabela 4 , tendo sido obtidas equações lineares e quadráticas. Pelas equa-

Tabela 3 - Resultados da análise de regressão para doses de substâncias húmicas das diversas matérias -primas testadas para as variáveis comprimento $(\mathrm{cm})$ e produção de matéria seca $(\mathrm{g})$ do sistema radicular

Table 3 - Results of polinomial regression analysis for humic compounds of different raw-materials tested on length (cm) and dry matter of root system $(\mathrm{g})$

\begin{tabular}{|c|c|c|c|}
\hline & $\begin{array}{l}\text { Comprimento do sistema radicular }(\mathrm{cm}) \\
\text { Length of root system }(\mathrm{cm})\end{array}$ & & \\
\hline $\begin{array}{l}\text { Matéria-prima } \\
\text { Raw-material source }\end{array}$ & $\mathrm{Y}$ & $\mathrm{P}$ & $\mathrm{R}^{2}$ \\
\hline $\begin{array}{l}\text { Palermo CE-4700 } \\
\text { Candiota CE-4700 } \\
\text { Leão CE-5200 } \\
\text { Candiota Camada Inferior } \\
\text { Candiota Camada Superior } \\
\text { Palermo CE-4200 } \\
\text { Candiota CE-3300 }\end{array}$ & $\begin{aligned} Y & =29.525,51+2648,414 X-58,8897 X^{2} \\
Y & =29.345,92+1865,113 X-26,2877 X^{2} \\
Y & =29.543,47+2484,283 X-53,0067 X^{2} \\
Y & =29.313,07+2143,287 X-41,4845 X^{2} \\
Y & =29.491,17+2173,447 X-41,1464 X^{2} \\
Y & =29.828,73+2601,813 X-58,1334 X^{2} \\
Y & =29.246,64+2100,633 X-38,1129 X^{2}\end{aligned}$ & $\begin{array}{l}(\mathrm{P}<0,01) \\
(\mathrm{P}<0,01) \\
(\mathrm{P}<0,01) \\
(\mathrm{P}<0,01) \\
(\mathrm{P}<0,01) \\
(\mathrm{P}<0,01) \\
(\mathrm{P}<0,01)\end{array}$ & $\begin{array}{l}0,99 \\
0,97 \\
0,97 \\
0,95 \\
0,98 \\
0,99 \\
0,95\end{array}$ \\
\hline & $\begin{array}{l}\text { Matéria seca do sistema radicular }(\mathrm{g}) \\
\text { Dry matter of root system }(\mathrm{g})\end{array}$ & & \\
\hline PalermoCE-4700 & $\mathrm{Y}=7,14+0,371 \mathrm{X}-0,0123 \mathrm{X}^{2}$ & $(\mathrm{P}<0,01)$ & 1,00 \\
\hline Candiota CE-4700 & $Y=7,25+0,343 X-0,0114 X^{2}$ & $(\mathrm{P}<0,01)$ & 1,00 \\
\hline Leão CE-5200 & $Y=7,18+0,232 X-0,0076 X^{2}$ & $(\mathrm{P}<0,01)$ & 1,00 \\
\hline Candiota Camada Inferior & $Y=7,23+0,366 X-0,0121 X^{2}$ & $(\mathrm{P}<0,01)$ & 1,00 \\
\hline Candiota Camada Superior & $\mathrm{Y}=6,89+0,425 \mathrm{X}-0,0137 \mathrm{X}^{2}$ & $(\mathrm{P}<0,01)$ & 0,85 \\
\hline Palermo CE-4200 & $Y=7,04+0,365 X-0,0119 X^{2}$ & $(\mathrm{P}<0,01)$ & 0,90 \\
\hline Candiota CE-3300 & $Y=7,28+0,308 X-0,0103 X^{2}$ & $(\mathrm{P}<0,01)$ & 0,98 \\
\hline
\end{tabular}

$X=$ dosagem de substância húmica ( 0, 10, 20 e 30-mg/L).

$X=$ humic compounds concentration ( $0,10,20$ and $30-\mathrm{mg} / \mathrm{L})$. 
ções de regressão obtidas, observa-se que o menor raio foi obtido na dose de $30 \mathrm{mg} / \mathrm{L}$. Assim estas dosagens foram eficientes para diminuir o raio médio das raízes, aumentando a eficiência na absorção de nutrientes, quando a dose utilizada passou de 0 para $30 \mathrm{mg} / \mathrm{L}$ (Tabela 4). Os coeficientes de determinação $\left(\mathrm{R}^{2}\right)$ obtidos indicam que mais de $90 \%$ da variação foi decorrente do efeito das doses aplicadas. Os resultados comprovam o maior desenvolvimento das raízes com menor raio em presença de substâncias húmicas, o que aumenta a eficiência das raízes. Assim, ficou demonstrado neste trabalho a necessidade do uso de dosagens superiores a $10-\mathrm{mg} / \mathrm{L}$, pois o raio médio diminuiu em $22,99 \%$, com o aumento das dosagens e o menor raio ocorreu com a maior dose. As curvas de regressão obtidas não permitem obter as doses que possibilitem obter raízes com o menor raio. O ponto de máximo raio foi obtido sem a utilização de substâncias húmicas nas testemunhas.

Superfície ocupada pelas raízes

A análise de variância para essa variável apresentou significância para o efeito da interação matéria-prima $\mathrm{x}$ doses $(\mathrm{P}<0,01)$, com $\mathrm{CV}(\mathrm{a})=2,09 \% \mathrm{e}$ $\mathrm{CV}(\mathrm{b})=4,85 \%$. As equações polinomiais da interação entre matérias-primas $\mathrm{x}$ doses utilizadas estão apresentadas na Tabela 4, tendo sido todas quadráticas. Esta variável é conseqüência do raio médio e da matéria verde produzida, tendo ambas sido influenciadas pelas doses utilizadas. As curvas de regressão apresentaram os seguintes pontos de máxima: Palermo CE-4700 (5.397,09 $\mathrm{cm}^{2}$ na dose de $19,18 \mathrm{mg}$ de carbono por litro); Candiota CE-4700 $\left(5.265,54 \mathrm{~cm}^{2}\right.$ na dose de 22,22 mg/L); Leão CE-5200 (5.273,85 cm na dosagem de 19,68 mg/L), Candiota Camada Inferior (5.177,46 cm na dose de 19,07 mg/L); Candiota Camada Superior $\left(5.179,29 \mathrm{~cm}^{2}\right.$ na dose $\left.20,36 \mathrm{mg} / \mathrm{L}\right)$; Palermo CE-4200 $\left(5.329,70 \mathrm{~cm}^{2}\right.$ na dosagem de $19,12 \mathrm{mg} / \mathrm{L})$ e Candiota CE-3300 (5.215,44 $\mathrm{cm}^{2}$ na dose de 21,06 mg/L). Os resultados mostram que a superfície ocupada pelas raízes foi influenciada diretamente pelas matérias-primas e pelas doses de substâncias húmicas utilizadas (todos com $\mathrm{R}^{2}<90 \%$ ). Ocorreu aumento de $68 \%$ na superfície ocupada pelas raízes, quando a dosagem de substâncias húmicas foi elevada de 0 para $20 \mathrm{mg} / \mathrm{L}$ (Tabela 4). Assim, como em diversos trabalhos (PINTON et al., 1992; HARPER et al., 1995; e SILVA et al., 1998b), também neste experimento os ácidos responderam

Tabela 4 - Análise de regressão para doses de substâncias húmicas das diversas matérias-primas testadas: raio médio (cm) do sistema radicular e superfície $\left(\mathrm{cm}^{2}\right)$ ocupada pelo sistema radicular

Table 4 - Polinomial regression analysis for humic compounds of different raw-materials tested: mean radius of root system (cm), occupied surface of root system $\left(\mathrm{cm}^{2}\right)$

\begin{tabular}{|c|c|c|c|}
\hline \multicolumn{4}{|c|}{$\begin{array}{l}\text { Raio médio do sistema radicular }(\mathrm{cm}) \\
\text { Mean radius of root system }(\mathrm{cm})\end{array}$} \\
\hline $\begin{array}{l}\text { Matéria-prima utilizada } \\
\text { Raw-material source (coals) }\end{array}$ & $\mathrm{Y}$ & $\mathrm{P}$ & $\mathrm{R}^{2}$ \\
\hline $\begin{array}{l}\text { Palermo CE-4700 } \\
\text { Candiota CE-4700 } \\
\text { Leão CE-5200 } \\
\text { Candiota Camada Inferior } \\
\text { Candiota Camada Superior } \\
\text { Palermo CE-4200 } \\
\text { Candiota CE-3300 }\end{array}$ & $\begin{array}{l}Y=0,017117-0,0001258 X \\
Y=0,017263-0,0000503 X-0,00000317 X^{2} \\
Y=0,017058-0,0001275 X \\
Y=0,017212-0,000038 X-0,00000367 X^{2} \\
Y=0,017193-0,000134 X \\
Y=0,016983-0,0001233 X \\
Y=0,017244-0,0000698 X-0,00000246 X^{2}\end{array}$ & $\begin{array}{l}(\mathrm{P}<0,01) \\
(\mathrm{P}<0,01) \\
(\mathrm{P}<0,01) \\
(\mathrm{P}<0,01) \\
(\mathrm{P}<0,01) \\
(\mathrm{P}<0,01) \\
(\mathrm{P}<0,01)\end{array}$ & $\begin{array}{l}0,99 \\
0,96 \\
0,99 \\
0,96 \\
1,00 \\
0,99 \\
0,93\end{array}$ \\
\hline \multicolumn{4}{|c|}{$\begin{array}{l}\text { Superfície ocupada pelo sistema radicular }\left(\mathrm{cm}^{2} / \mathrm{vaso}\right) \\
\text { Occupied surface of root system }\left(\mathrm{cm}^{2} / \text { pot }\right)\end{array}$} \\
\hline $\begin{array}{l}\text { Matéria-prima utilizada } \\
\text { Raw-material source (coals) }\end{array}$ & $\mathrm{Y}$ & $\mathrm{P}$ & $\mathrm{R}^{2}$ \\
\hline $\begin{array}{l}\text { Palermo CE-4700 } \\
\text { Candiota CE-4700 } \\
\text { Leão CE-5200 } \\
\text { Candiota Camada Inferior } \\
\text { Candiota Camada Superior } \\
\text { Palermo CE-4200 } \\
\text { CandiotaCE-3300 }\end{array}$ & $\begin{array}{l}Y=3214,021+227,608 X-5,9326 X^{2} \\
Y=3209,829+185,039 X-4,1639 X^{2} \\
Y=3206,595+210,104 X-5,3384 X^{2} \\
Y=3206,794+206,724 X-5,4213 X^{2} \\
Y=3187,320+195,709 X-4,8070 X^{2} \\
Y=3222,141+220,469 X-5,7657 X^{2} \\
Y=3213,477+190,112 X-4,5134765 X^{2}\end{array}$ & $\begin{array}{l}(\mathrm{P}<0,01) \\
(\mathrm{P}<0,01) \\
(\mathrm{P}<0,01) \\
(\mathrm{P}<0,01) \\
(\mathrm{P}<0,01) \\
(\mathrm{P}<0,01) \\
(\mathrm{P}<0,01)\end{array}$ & $\begin{array}{l}1,00 \\
0,99 \\
0,98 \\
0,98 \\
0,97 \\
0,99 \\
0,99\end{array}$ \\
\hline
\end{tabular}

$\mathrm{X}=$ dose de substância húmica utilizada $(0,10,20$ e $30-\mathrm{mg} / \mathrm{L})$.

$X=$ humic compounds concentration $(0,10,20$ and $30-\mathrm{mg} / \mathrm{L})$. 
positivamente até determinada dosagem, a partir da qual mostraram efeito deletério sobre o desenvolvimento das raízes. As substâncias húmicas presentes na solução em dosagem mais elevadas apresentaram mais ligantes que os íons metálicos presentes na solução para poderem ser complexados e se tornarem menos disponíveis para as raízes das plantas, inibindo o desenvolvimento das mesmas (RHAUTHAN e SCHNITZER, 1981). Estas substâncias possibilitam maior desenvolvimento das raízes em cultivos em solução nutritiva que utilizem areia como substrato (DAVID et al., 1994; AYUSO et al., 1996; e SILVA et al., 1998c). Podem ser utilizadas na produção de forragem, flores, frutas e hortaliças em sistemas de produção hidropônicos e em fruticultura, floricultura e horticultura utilizando a técnica do gotejamento. Esse material possibilita maiores produções, devido ao estímulo destas substâncias sobre as raízes, absorção de nutrientes e desenvolvimento da parte aérea.

\section{Conclusões}

O desenvolvimento das raízes da planta forrageira azevém foi estimulado pelas substâncias húmicas.

As diversas fontes de substâncias húmicas utilizadas influenciaram porém de forma diferente os parâmetros das quatro variáveis analisadas.

\section{Agradecimento}

À Fundação de Amparo à Pesquisa do Estado do Rio Grande do Sul (FAPERGS), à Fundação Banco do Brasil e à Empresa JOSAPAR, pelo aporte financeiro.

Ao Departamento de Solos da Universidade Federal do Rio Grande do Sul, pelo apoio prestado na execução deste trabalho.

\section{Referências Bibliográficas}

AYUSO, M., HERNANDEZ, T., GARCIA, C. et al. 1996. Stimulation of barley growth and nutrient absorption by humic substances originating from various organic materials. Bioresour Technol., 57(3): 251-257.

BRUN, G. Pouvoir complexant des matieres humiques effets sur l'alimentation minerale des vegetaux. Toulouse, France, Institut National Polytechnique de Toulouse, 1993. 139p Thèse de Douctorat, Specialite: Traitement des matieres premieres vegetales - Institut National Polytechnique de Toulouse, 1993.

DAVID, P. P., NELSON, P. V., SANDERS, D. C. 1994. A humic acid improves growth of tomato seedling in solution culture, J. Plant Nut., 17(1):173-184.
GOENADI, D.H., SUDHARAMA, I.M. 1995. Shoot initiation by humic acids of selected tropical crops grown in tissue culture. Plant and cell response, 15(1/2):59-62.

HARPER, S.M., EDWARDS, D.G., KERVEN, G.L. et al. 1995. Effects of organic acid fractions extraced from Eucalyptus camaldulencis leaves on root elongation of maize (Zea mays) in the presence and absence of aluminium. Plant and soil, 171:189-192.

HAYES, M.H.B. MACCARTHY, P., MALCOLM, R.L. et al. 1989. Humic substances. II. In search of structure. West Sussex, UK: John Wiley \& Sons Ltd. 733p.

KHRISTEWA, L.A. The participation of humic acids and their practical use in the Ukraine. In: INTERNATIONAL PEAT CONGRESS, 2, 1953, Leningrad. Proceedings... Leningrad: Soviet Union Academy of Sciences/Peat International Society, 1953. p.543-558.

MAGGIONI, A., VARANINI, Z., NARDI, S. et al. 1987. Action of soil humic matter on plant roots: stimulation of ion uptake and effects on $\left(\mathrm{Mg}^{2+}+\mathrm{K}^{+}\right)$ATPase activity. Science of the Total Environment, 62: 355-363.

PEREIRA, J.R., MÉNDEZ, J. 1976. Inibition of peroxidase by algal humic and fulvic acids. Biologic Plants, 1:171-182.

PETROVIC, P., VITOROVIC, D., JABLANOVIC, M. 1982. Investigations of biological effects of humic acids. Acta Biol. Med. Exp., 7: 21-25.

PINTON, R., VARANINI, Z., VIZZOTTO, G. et al. 1992. Soil humic substances affect transport properties of tonoplast vesicles isoated from oat roots. Plant and Soil, 142: 203-210.

POSPÍSIL, F., HRUBCOVA, M. 1974. The effectr of humic acids and their fractions on the phytase activity. Ved. Pr. Vyzk. Ustavu Rostl. Vyrob., 18:47-54.

RAM, N., VERLOO, M. 1983. Effect of natural complexants on the uptake of trace elements by barley and their extractable amounts in soil. Agrochimica, 28:13-19.

RAUTHAN, B.S., SCHNITZER, M. 1981. Effects of a soil fulvic acid on the growth and nutrient content of cucumber (Cucumis sativus) plants. Plant and Soil., 63:491-495.

SAMSON, G., VISSER, S.A. 1989. Surface-active effect of humic acids on potato cell membrane properties. Soil Biology Biochemistry., 21:343-347.

SCHNITER, M., SCHUPPLI, P. 1989. The extractio of organic matter from selected soils and particle size fractions with 0.5 $\mathrm{M} \mathrm{NaOH}$ and $0.1 \mathrm{M} \mathrm{Na}_{4} \mathrm{P}_{2} \mathrm{O}_{7}$ solutions. Canadian Journal of Soil Science, 69: 253-262.

SILVA, R.M., JABLONSKI, A ., TEIXEIRA LESSA, R.N. et al. 1995a. Produção de ácidos húmicos e fúlvicos a partir de diferentes matérias-primas orgânicas. Rev. Escola de Engenharia, 23(2):53-60.

SILVA, R.M., JABLONSKI, A., TEIXEIRA LESSA, R.N. et al. 1995b. Produção e características físico-químicas dos extratos das substâncias húmicas extraídos de diferentes fontes de matéria prima. EGATEA: Rev. Escola de Engenharia, 23(2):61-69.

SILVA, R.M., JABLONSKI, A. 1995. Uso de ácidos húmicos e fúlvicos em solução nutritiva na produção de alface. Rev. Escola de Engenharia, 23(2):71-78.

SILVA, R.M., JABLONSKI. A., SIEWERDT, L. et al. Desenvolvimento do sistema radicular do azevém sob influência de diferentes fontes e dosagens de substâncias húmicas. In: REUNIÃO ANUAL DA SOCIEDADE BRASILEIRA DE ZOOTECNIA, 35, 1998, Botucatu. Anais... Botucatu: FMVZUNESP-SBZ, 1998a. p.357-359.

SILVA, R.M., JABLONSKI. A., SIEWERDT, L. et al. Desenvolvimento do sistema radicular da aveia sob influência de 
Rev. bras. zootec.

diferentes fontes e dosagens de substâncias húmicas. In: REUNIÃO ANUAL DA SOCIEDADE BRASILEIRA DE ZOOTECNIA, 35, 1998, Botucatu. Anais... Botucatu: FMVZUNESP-SBZ, 1998b. p.412-414.

SILVA, R.M., JABLONSKI. A., SIEWERDT, L. et al. Desenvolvimento do sistema radicular do milho sob influência de diferentes fontes e dosagens de substâncias húmicas. In: REUNIÃO ANUAL DA SOCIEDADE BRASILEIRA DE ZOOTECNIA, 35, 1998, Botucatu. Anais... Botucatu: FMVZUNESP-SBZ, 1998c. p.684-686.

SMÍDOVÁ, M. The influence of humic acid on the respiration of plant roots. 1960. Biol. Plant., 2:152-164.

TEDESCO, M.J., GIANELLO, C., BISSANI, C.A. et al. 1995. Análises de solo, planta e outros materiais. Porto Alegre: UFRGS. Faculdade de Agronomia. Departamento de Solos, 174p. (Boletim Técnico, n.5, 2.ed. )
1631

TENNANT, D. A test of a modified line intersect method of estimating root length. 1975. J Ecol., 63:995-1000.

VAUGHAN, D., ORD, B.G. 1980. An effect of soil organic matter on invertase activity in soil. Soil Biology Biochemistry, 12:449-450.

XUDAN, X. 1986. The effect of foliar application of fulvic acid on water use, nutrient uptake and yield in wheat. Australian J. Agric. Res., 37:343-350.

ZONTA, E.P., MACHADO, A.D. 1984. SANEST, Sistema de Análise Estatística para microcomputadores. Pelotas, RS: UFPel. 75p.

Recebido em: $14 / 10 / 98$

Aceito em: 19/06/00 